\title{
ANALYSIS OF CONVEYOR BELT WEAR CAUSED BY MATERIAL ACCELERATION IN TRANSFER STATIONS
}

\section{Błażej DOROSZUK* Robert KRÓL}

Faculty of Geoengineering, Mining and Geology, Wrocław University of Science and Technology, Wybrzeże Stanisława Wyspiańskiego 27, 50-370 Wrocław, Poland

\begin{abstract}
In conveyor transport systems, different solutions to the transfer points constructions are used. Choosing the right solution requires conditions analysis of the cooperation between two conveyors. For years, the analytical methods have been used to evaluate the discharge trajectory of the transported material. Increasingly, to evaluate the movement of grains in the transfer space to analyze the behavior of the bulk material in contact with transfer chute elements, researchers successfully use simulations performed in the discrete element method (DEM). Well-constructed chute allows the material stream to be uniformly fed onto the receiving conveyor with a desired stable tangential speed. Proper design reduces motion resistances and belt wear. In the paper, the analysis of selected construction solutions of transfer points and the possibilities of their usage in copper ore transport systems were performed. The research was conducted using the DEM simulations of the ore flow. For specifying the best conditions of the cooperation of the feeding and receiving conveyors, a series of simulations were generated. The criteria for the comparative evaluation of the analyzed solutions were the values of acceleration zone length and abrasive wear of the belt.
\end{abstract}

Keywords: conveyor transfer station, discrete element method, acceleration length, abrasive wear

\section{INTRODUCTION}

Transfer stations play an essential role in conveyor transport systems. Their primary task is to pass on the ore from a feeding conveyor centrally to the receiving belt in

\footnotetext{
* Corresponding author: blazej.doroszuk@gmail.com (B. Doroszuk)
}

doi: $10.37190 / \mathrm{msc} 192615$ 
such a manner that the material velocity in the direction of a belt travel is, as nearly as possible, equal to the velocity of the belt itself. Each construction solution has its advantages and disadvantages and choosing the right one requires a detailed analysis of the conditions in which the conveyors cooperate. The setting of transfer point elements should be decided based on the predicted discharge trajectory. The particle path of movement can be determined based on analytical methods (CEMA 2002) on the grounds of simple physical dependencies. Another way to determine the particle trajectory, also considering the interparticle interaction, are simulation methods. Leading method for simulating bulk material behavior is a discrete element method (DEM). Increasingly this method is used to determine the movement of grains in the transfer space (Czuba, Furmaniak 2013; Ilic, Wheeler 2017) and to analyze the behavior of bulk material in contact with transfer chute elements (Hastie, 2013).

The proper transfer point design allows the material stream to be uniformly fed on the receiving conveyor with a desired stable tangential speed. Well-constructed transfer station reduces motion resistances and belt wear. Each lump falling on the belt at a certain speed must be accelerated to the belt speed $v_{b}$. On the acceleration zone length, the frictional force between the material particles and the belt must overcome the lifting resistance of the material resulting from the conveyor angle and frictional resistance between the material and skirt boards (Gładysiewicz 2003). Furthermore, durability is a parameter of crucial importance for the annual total costs of belt and splice replacement, hence wear degree should be monitored (Jurdziak et al. 2019).

Poorly constructed transfer point can result in several adverse events, such as blockage causing downtime, large lumps falling from the height creating cuts in a conveyor belt, long acceleration zone generating big abrasive wear and significant motion resistances, and uneven material distribution resulting in irregular abrasion of the belt. The paper focuses on the analysis of the acceleration zone length and values of the abrasive wear. The research was conducted using the DEM simulations of the ore flow. For specifying the best conditions of the cooperation of the feeding and receiving conveyors, a series of simulations were generated.

Analysis of the phenomenon occurring between the transported material and the elements of the transfer station is increasingly the subject of research conducted by many scientists. The latest scientific works in this field use DEM and focus on the modeling material flow and wear analysis. In the paper Modelling bulk solid flow interactions in transfer chutes: Shearing flow, the authors concentrate on the observation of fastmoving, high volume coal stream in the restricted space, where the internal bulk material properties affect the mode of flow. The study compares the application of the traditional and modified continuum method approach to DEM simulations and site observation (Ilic et al. 2019). The different research focuses on wear in iron ore transfer chutes and attempts to propose design criteria for reducing wear (Ilic 2019). Wear can also be caused by conveyor equipment. Analysis of abrasive wear generated by scraper in coal handling was performed in the paper (Xia et al. 2019). 


\section{CASE STUDY}

In the Polish underground copper ore mines in the case of angled transfer, constructions with rock boxes are widely used (Fig. 1). The primary role of the rock box is to: capture the incoming material stream, fill up the box to a particular volume, and direct down sliding material onto the lower conveyor belt. The partially filled box creates particle/particle interaction instead of particle/wall interactions (Hastie 2013). This solution limits the wear of the construction elements (Hastie 2013), but on the other hand, the particle velocity in the direction of receiving belt motion is almost equal to zero.

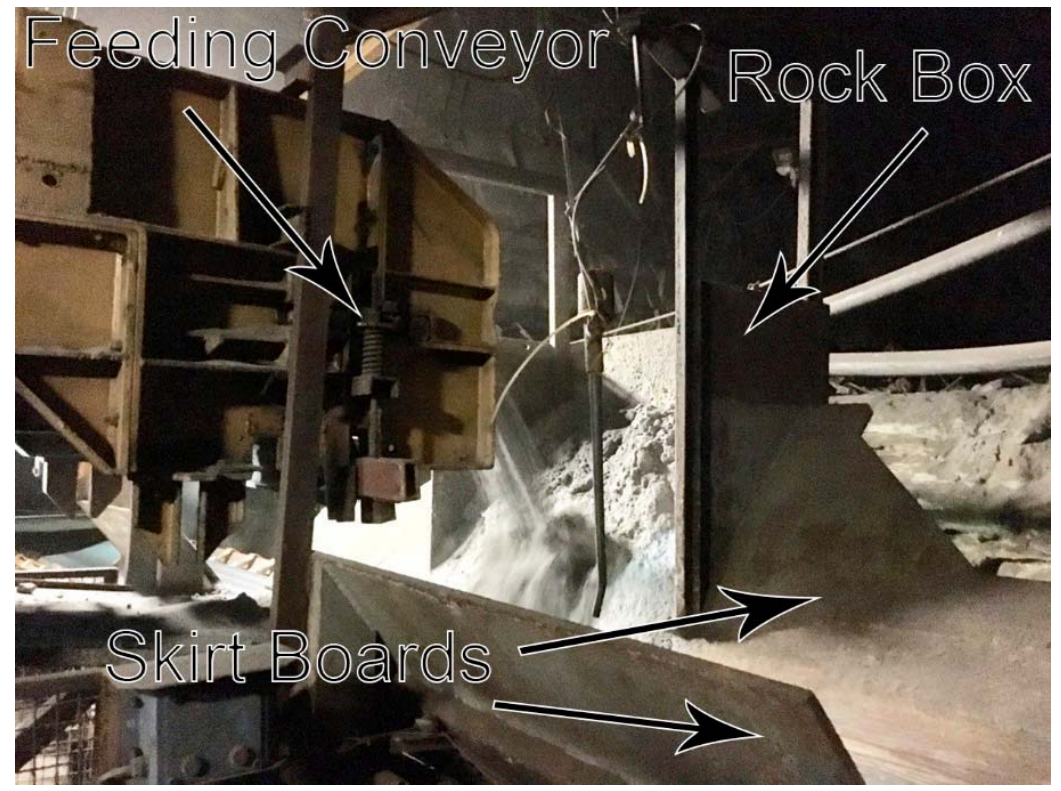

Fig. 1. A transfer station with rock box in underground mine

In the paper, angled transfer point with belt conveyors set perpendicular to each other was selected for analysis. The location of feeding conveyor over the receiving one, in the underground mine, is limited by transfer point elements and the height of the transport tunnel. The feeding conveyor was placed $1.8 \mathrm{~m}$ above the receiving one (Fig. 2), because in the analyzed example with the rock box, it was the approximate the lowest possible position limited by skirt boards. The belts $(1 \mathrm{~m}$ wide) were moving at a speed of $v_{b}=2.5 \mathrm{~m} / \mathrm{s}$. Using the relations described in the book (Gladysiewicz 2003), the maximum capacity of the analyzed conveyor was determined at the level of $Q \approx 500 \mathrm{~kg} / \mathrm{s}$. In the analysis, fully loaded feeding conveyor transfers material to the empty receiving belt. 


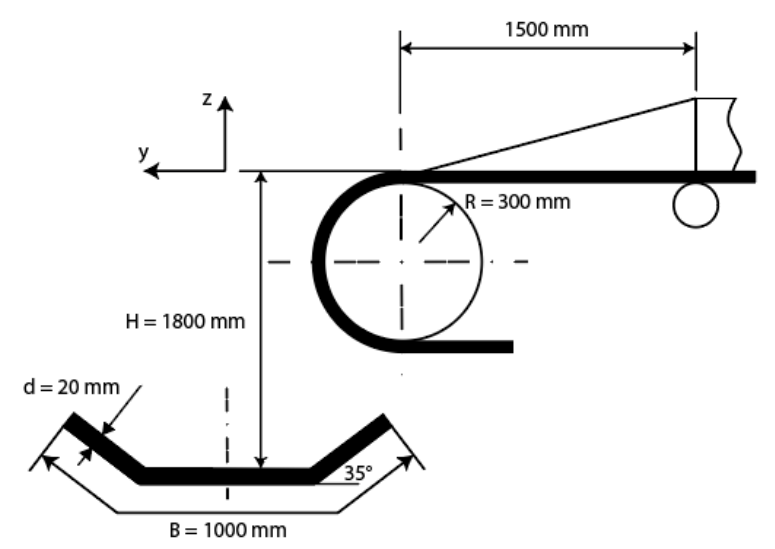

Fig. 2. Cooperation conditions of two conveyor belts

Using DEM software, simulation of the ore discharging from the feeding conveyor was generated. Half the mass of modeled copper ore consisted of $5 \mathrm{~cm}$ particles and the other half of $10 \mathrm{~cm}$ solids. Parameters of the material from own earlier research were employed (Doroszuk et al. 2019). After the simulation, the mass center positions of the particles directly above the head pulley axis were recorded. Positions readings were done for 50 time-steps at $0.1 \mathrm{~s}$ intervals. The readout was compared with the analytical method (CEMA, 2002) allowing to determine the approximate geometry of the material cross-section over the head pulley and the height of the ore stream (Fig. 3). Knowledge of the stream height is a useful parameter for the design process of the hood and spoon type transfer point. The hood must have dimensions big enough to capture the entire stream of ore and the proper curvature to redirect it down.

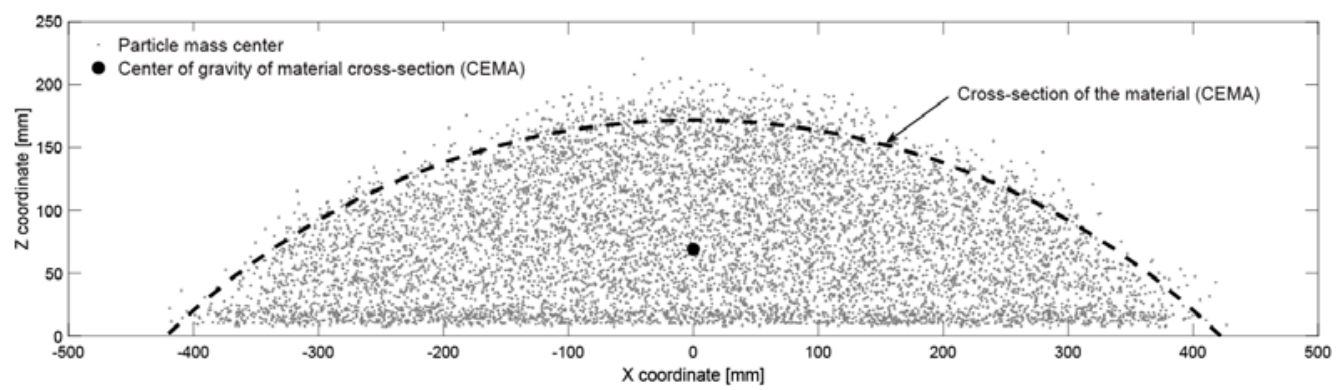

Fig. 3. The readout of the particles' positions over the head pulley compared with a cross-section of the material stream accordant to CEMA

The trajectory of the discharged stream of ore obtained from the simulation was compared with the movement path of the particle falling directly from the level of the conveyor belt (Fig. 4). The particle lying on the belt has a horizontal velocity equal to 
the speed of the belt and the equations of free body fall describe the vertical velocity. The mathematically determined particle movement curve very well represents the lower limit of the falling stream of transported material. The particles after falling $1.8 \mathrm{~m}$ down, reached the speed of $7 \mathrm{~m} / \mathrm{s}$. The transfer height should be, if possible, minimize in the case of side loading. In the case of central loading with redirecting material parallel to the receiving belt, the height should be set such a way that the potential energy of material changing in the kinetic energy will fill losses in kinetic energy caused by friction on transfer station elements.

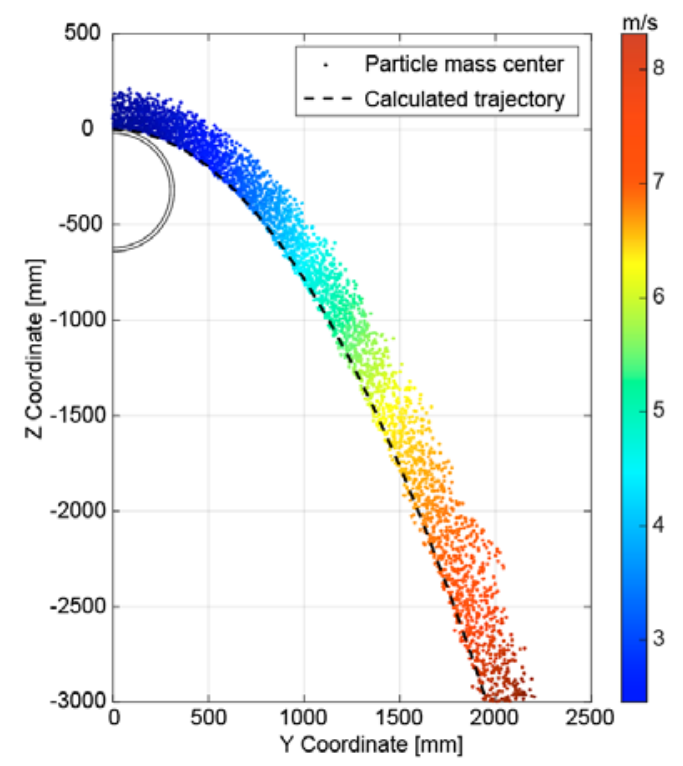

Fig. 4. Discharge trajectory of the copper ore particles falling from the feeding conveyor with initial horizontal speed $v=2.5 \mathrm{~m} / \mathrm{s}$ - comparison of DEM particle positions with the calculated trajectory

\section{SELECTED CONSTRUCTIONS AND COMPARATIVE EVALUATION}

\subsection{TRANSFER POINT CONSTRUCTIONS}

Depending on the cooperation conditions of the feeding and receiving conveyors, various kinds of transfer chute stations are used. The leading three solutions are: impact plates, chutes (straight or curved), and rock boxes (Czuba, Furmaniak 2013). The first simulation was made for the transfer point with the rock box used in the mine (Fig. 5). The box was $714 \mathrm{~mm}$ tall, $1680 \mathrm{~mm}$ wide and $850 \mathrm{~mm}$ deep. The box was placed on the side of the receiving belt. On both sides of the lower located conveyor, there were skirt boards made of inclined steel plates with a rubber strap attached to the bottom. 


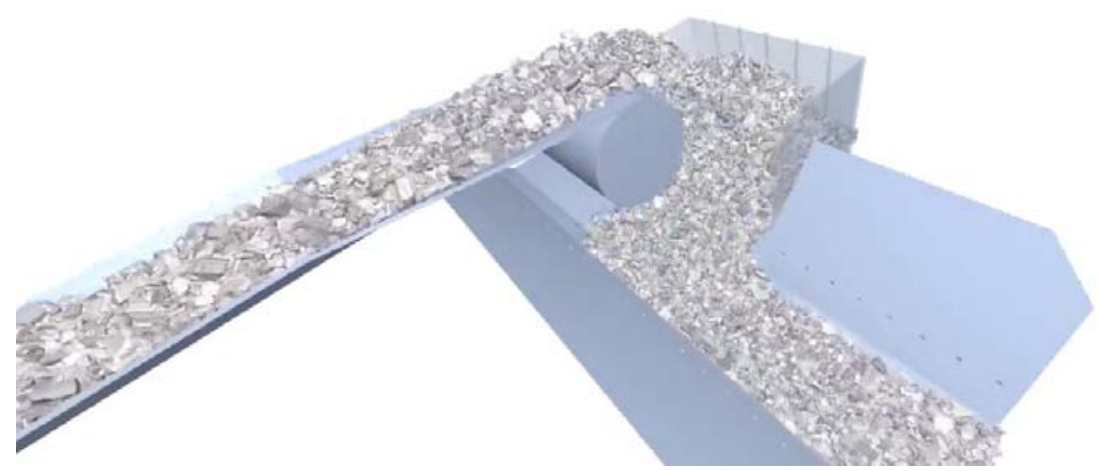

Fig. 5. Simulation of material transfer through the transfer station with rock box

The first alternative solution was the original design inspired by a hood and spoon type transfer chute (Fig. 6a). It consisted of two steel elements. The purpose of each element was to change the direction of the ore stream by 90 degrees. Proper falling material capture, with a small impact angle, allowed to change the direction of the ore flow without significantly decelerating it. The lower element consisted of an inclined steel sheet, on which the material was falling and sliding onto receiving conveyor. The sheet was profiled in such a way that the rounded edge changed the vector of the particle velocity into a parallel to the belt movement direction. The advantage of this solution is that the kinetic energy is not entirely lost and due to the change in the di rection of the velocity vector, the particles do not have to be accelerated from $0 \mathrm{~m} / \mathrm{s}$ to the speed of the belt. The disadvantage of this solution is, however, the more significant abrasion of the chute elements.

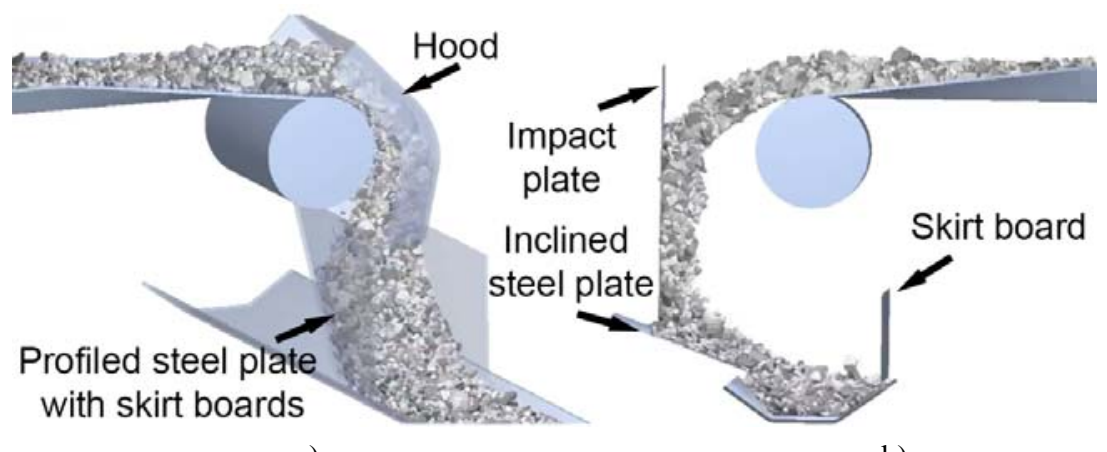

a)

b)

Fig. 6. Alternative solutions:

a) original design inspired by hood and spoon type transfer chute, b) impact plate

The second alternative to the prior transfer points was the impact plate (Fig. 6b). An impact plate should be regarded and designed as a consumable item. With the correct 
geometry and material choice, the plate may provide agreeable durability against impact and abrasive wear (Scott, Choules 1993). Numerous diverse geometric designs of impact plates in combination with lining materials varying from ceramics, ferrous wear-resistant products, plastics, rubber liners, and rubber sheets have been successful (Scott, Choules 1993). In the analysis, the plate was made of a conveyor belt, $1.5 \mathrm{~m}$ tall and $1.2 \mathrm{~m}$ wide. The stream of ore impacted the hanging belt, lost its kinetic energy, and then the slowed bodies felt freely down to the steel plate, on which they slide onto the receiving conveyor. The advantage of this solution is that the kinetic energy is lost on the impact plate, not on the conveyor belt, but the disadvantage is that the material has to be accelerated nearly from $0 \mathrm{~m} / \mathrm{s}$ to the speed of the belt and that the loading area of the belt is much longer than in the case of previous solutions.

\subsection{COMPARATIVE EVALUATION}

Choosing the right solution requires a comparison of the analyzed cases. The goal of designing a transfer station is an optimum material flow with (Kessler, Prenner 2009):

- constant speed,

- low impact,

- low wear on chute lining and at discharge location,

- low dust emission,

- low noise emission.

The comparison of transfer stations with side loading to those with central loading requires a detailed analysis of many aspects. In the case of central loading (Fig. 7), recording parameters such as the length of the acceleration zone or the tangential and perpendicular, to the belt, exit speed is not a difficult task, however, in the case of side

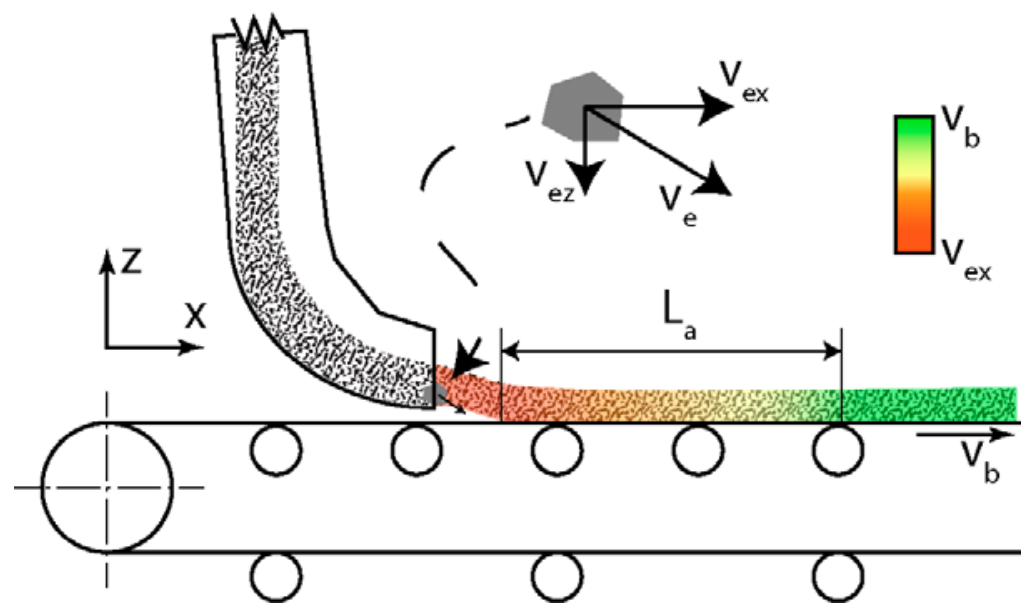

Fig. 7. Parameters obtained during the analysis of centrally located transfer station 
loading, these values are not unambiguous. For this reason, individual numerical values describing the material stream could not be compared. Therefore, the distributions of the parameters' values in the loading area were examined. Thanks to the knowledge of particle velocity distribution, it was possible to determine the length of the acceleration zone, abrasive wear of the belt, or acceleration resistances.

The acceleration zone length can be theoretically calculated in the case of central loading (Gładysiewicz 2003). For obtaining that value in the functioning transfer station, pellets with accelerometer could be used.

In the case of belt wear analysis in the loading areas, there are four leading causes (Hustrulid 1998):

- wear between the skirts and the belt,

- material trapped between the skirts and the belt,

- cover damage resulting from material impacting the receiving conveyor belt at high speeds,

- wear from the turbulence of bringing the material up to the belt speed. All or none of these causes can contribute to belt wear (Hustrulid 1998).

In some transfer points, the material with high velocity hits the belt. The material energy is not being removed or redirected be the transfer station elements as it should in these cases. The covers of the belt are absorbing the energy. It may cause increased wear. If the impact bed placed under a conveyor in the loading area is very rigid, it increases the possibility of damage to the belt (Hustrulid 1998).

The ore falling onto the receiving belt must be accelerated up to belt speed. Acceleration occurs thanks to the frictional force acting between the material and the belt cover. Before the material reaches the belt speed and quiets down, it can be turbulent. The turbulence can contribute to belt wear. In perfect conditions the ore would be lightly placed, fines first, already up to the speed of receiving belt. When the material hits the belt with a high downward speed, the turbulence is created from impacts at that speed (Hustrulid 1998).

In the research paper (Roberts, Wiche 1999) focused on the analysis of the interaction between the geometry of the chute and the abrasive wear of the belt, the Eq. (1) to calculate the abrasive wear was presented. The abrasive wear resulted from the acceleration of particles, and loss of vertical component of the kinetic energy on the belt.

$$
W_{a}=\mu_{b} \rho v_{e z}^{2}\left(v_{b}-v_{e x}\right),\left[\mathrm{kPa} \frac{\mathrm{m}}{\mathrm{s}}\right]
$$

where:

$\mu_{b}-$ frictional coefficient between the bulk solid and conveyor belt, [-],

$\rho$ - bulk density, $\mathrm{kg} / \mathrm{m}^{3}$,

$v_{b}-$ belt speed, $\mathrm{m} / \mathrm{s}$,

$v_{e z}-$ vertical component of the exit velocity, $\mathrm{m} / \mathrm{s}$,

$v_{e x}-$ horizontal component of the exit velocity, $\mathrm{m} / \mathrm{s}$. 
A significant element to investigate when analyzing the transfer station is a lateral force. The amount of force that material puts on the belt that would tend to mistrack the belt is called lateral force. The preferable case is when that force is equal to 0 , though in $90^{\circ}$ transfer point it may not be possible. The combination of lateral force and belt tension will affect how big belt mistracking at the transfer station will occur (Hustrulid 1998). An additional factor affecting the belt mistrack is how well the belt is centrally loaded. That factor can be measured based on the calculation of the moment arm of the forces acting in the vertical direction (Hustrulid 1998).

Next important comparison parameters are motion resistances. In the group of concentrated resistances, the most critical component is the resistance occurring at the place of feeding the material onto the conveyor belt. That resistance consists of lifting resistance, acceleration resistance, and frictional resistance between material and skirt boards. The acceleration resistance depends on the conveyor capacity, the speed of the receiving belt, and the parallel to the belt material exit speed. That resistance is described by the equation (Gładysiewicz 2003):

$$
W_{z}=Q_{m} \frac{2\left(v_{b}-v_{e x}\right)}{v_{b}+v_{e x}} v_{b},[\mathrm{~N}]
$$

where $Q_{m}$ - conveyor belt capacity, $\mathrm{kg} / \mathrm{s}$.

The actual run-of-mine ore grain size distribution was not applied in the simulations, because it is easier to analyze the velocities of the particles with a similar diameter. The impact forces were not taken into account while calculating the abrasive wear of the belt, so lack of large solids did not affect the analysis results.

\section{RESULTS ANALYSIS}

From the same second of each DEM simulation, after stabilization of the ore stream on the conveyor belt (Fig. 8), the position and speed values of particles lying up to $10 \mathrm{~cm}$ above the belt were recorded. The obtained values were used to determine the distribution of particles velocity and abrasive wear.

The distributions were projected onto the horizontal XY plane (Figs. 9 and 10). Particles velocities parallel to the belt speed were shown in Fig. 9. In the case of side loading, the velocity distribution on the belt was very heterogeneous and it was not possible to determine the exit speed of the ore stream. Regarding the length of the acceleration zone, the shortest was in the case of hood and spoon transfer station, the longest in case of impact plate, and the standard solution acceleration zone length was in between.

The most significant abrasive wear was observed in the conventional solution with a rock box, used in copper ore mines (Fig. 10). The maximum recorded values were over four times greater than those for the alternative solution of the hood and spoon inspired transfer station design. In the case of the rock box and impact plate, the most 
significant abrasive wear occurs close to the loading side, and for the hood and spoon, the abrasion is evenly distributed along the width of the belt.

a)
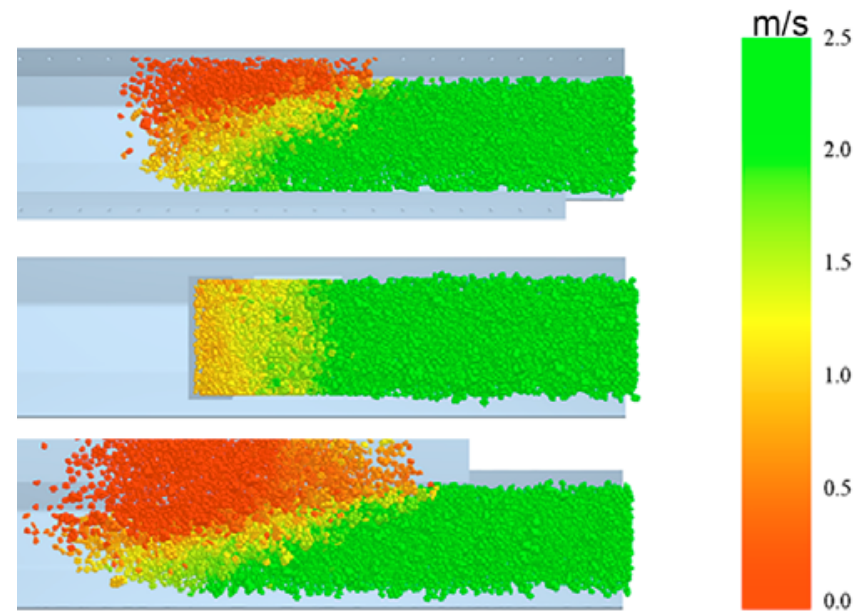

Fig. 8. The velocity of the particles: a) rock box, b) hood and spoon, c) impact plate
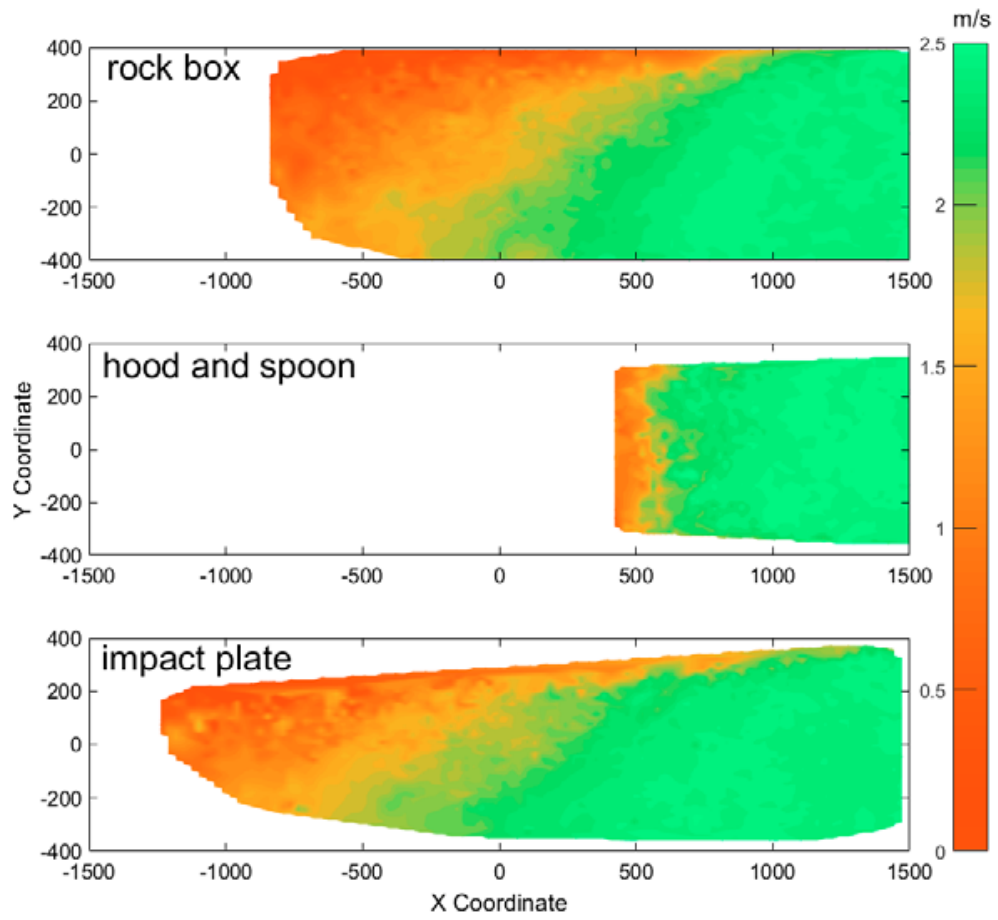

Fig. 9. The acceleration zone of particles lying at the belt 

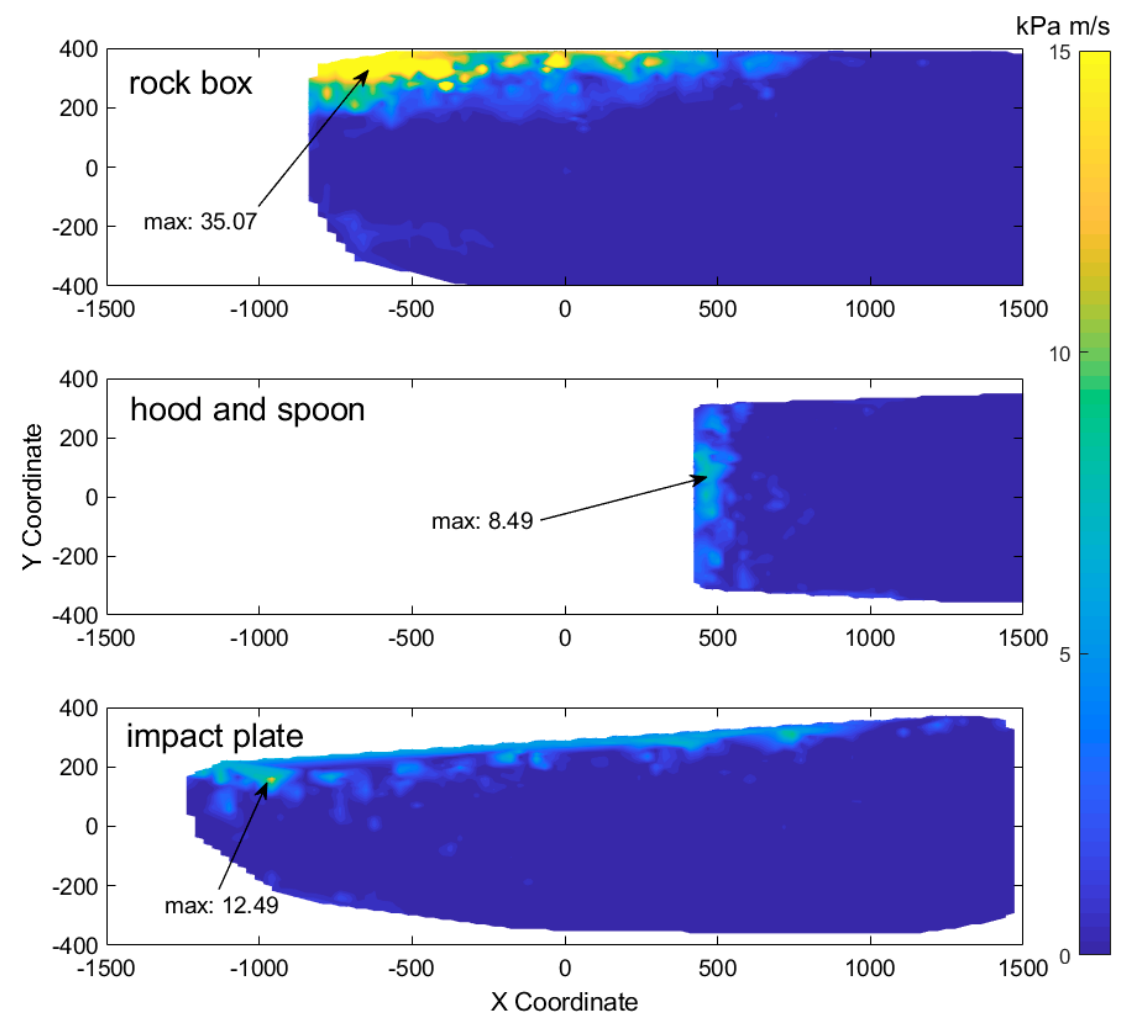

Fig. 10. Distribution of the abrasive wear of the belt for all analyzed transfer station constructions

The presented method only allows for displaying approximate concentrations of abrasive wear. A more accurate analysis of that distribution requires the development of dependencies considering the inclination of the belt over the side idlers and the forces acting on the belt from particles. The same in the case of comparison motion resistances occurring in the loading area, a new calculation method had to be developed.

\section{CONCLUSION}

The paper presents a suitability analysis of the different angled transfer stations in copper ore transport system. The research was carried out using the DEM simulation of material flow. For determining the optimal cooperation conditions between conveyor belts, a series of simulations were performed. In order to obtain a cross-section of the calibrated material over the head pulley and the material discharge trajectory, simulations of discharging the feeding conveyor were performed. Then the coordi- 
nates of the selected particles were exported. Good agreement between particles positions readouts with analytically calculated cross-section over the head pulley and discharge trajectory was obtained.

Three design variants of the $90^{\circ}$ transfer station, receiving the ore from the feeding conveyor operating at maximum capacity, were analyzed. The first design solution used in copper ore mines was the transfer point with a rock box. Alternatives to this solution were the original design inspired by hood and spoon type transfer chute and the impact plate. For comparison of these solutions, the length of the acceleration zone and abrasive wear of the belt were selected as criteria.

Obtained data from particles lying up to $10 \mathrm{~cm}$ above the belt were presented in the form of values distributions projected onto the horizontal plane. Side loading in the case of rock box and impact plate resulted in a long and uneven acceleration zone and larger abrasive wear values located mainly on the feeding side of the belt. Central loading of the receiving conveyor, with the use of the original proposed solution, allowed to shorten the acceleration zone significantly. This construction of transfer point reduced the maximum values of abrasive wear by more than four times when compared with standard construction with rock box.

A more accurate analysis of that distribution requires the development of dependencies considering the inclination of the belt over the side idlers and the forces acting on the belt from particles, so size distribution and impacts of the larger solids could be taken into account. The same in the case of comparison motion resistances occurring in the loading area, a new calculation method had to be developed.

In conclusion, the optimal solution for the transfer station, working in analyzed conditions, are central loading of the receiving belt, material exit velocity parallel and close to the belt speed, and even distribution of material over the entire belt width. Such conditions can be obtained by using hood and spoon transfer point.

\section{ACKNOWLEDGMENTS}

This work is partially financed from the statutory research grant No. 049u/0098/19 funded by the Ministry of Science and Higher Education.

\section{REFERENCES}

CEMA, 2002, Belt conveyors for bulk materials, Conveyor Equipment Manufacturers Association, 5th ed. CZUBA W., FURMANIAK K., 2013, Analysis of a grain motion in the transfer area of the belt conveyor, Eksploatacja i Niezawodność - Maintenance and Reliability, Vol. 15, No. 4, 390-396.

DOROSZUK B., WALKER P., KRÓL R., 2019, Badania własności zróżnicowanej litologicznie rudy miedzi na potrzeby modelowania DEM, CUPRUM - Czasopismo Naukowo-Techniczne Górnictwa Rud, Vol. 90, No. 1, 5-19.

GŁADYSIEWICZ L., 2003, Przenośniki taśmowe: teoria i obliczenia, Oficyna Wydawnicza Politechniki Wrocławskiej, Wrocław. 
HASTIE D., 2013, An experimental and simulated investigation of particle flow through a conveyor rock box. ICBMH 2013, 11th International Conference on Bulk Materials Storage, Handling and Transportation.

HUSTRULID A., 1998, Transfer Station Analysis. Proceedings of the Annual Meeting of the Society of Mining Engineers (SME), 33-53.

ILIC D., WHEELER C., 2017, Transverse solid behavior during discharge from troughed belt conveyors, Advanced Powder Technology, Vol. 28, 2410-2430.

ILIC D., ROBERTS A., WHEELER C., KATTERFELD A., 2019, Modelling bulk solid flow interactions in transfer chutes: Shearing flow, Powder Technology, Vol. 354, 30-44.

ILIC D., 2019, Development of design criteria for reducing wear in iron ore transfer chutes, Wear, Vol. 434-435.

JURDZIAK L., BAJDA M., BŁAŻEJ R., 2019, Estimation of Purchase and Replacement Costs of Conveyor Belts and their Splices in an Underground Mine Based on their Durability, IOP Conf. Ser.: Earth Environ. Sci., 221.

KESSLER F., PRENNER M., 2009, DEM - Simulation of Conveyor Transfer Chutes, FME Transactions, Vol. 37, 185-192.

ROBERTS A., WICHE S., 1999, Interrelation Between Feed Chute Geometry and Conveyor Belt Wear, Bulk Solids Handling, Vol. 19, No. 1, 35-39.

SCOTT O., CHOULES P., 1993, The use of impact plates in conveyor transfers, Tribology International, Vol. 26, No. 5, 353-359.

XIA R., WANG X., LI B., WEI X., YANG Z., 2019, Discrete Element Method- (DEM-) Based Study on the Wear Mechanism and Wear Regularity in Scraper Conveyor Chutes, Hindawi Mathematical Problems in Engineering. 